\title{
"La Commedia umana" di Balzac. Omaggio al romanziere assoluto, a cura di Alessandro Demma
}

\section{Marco Stupazzoni}

\section{(2) OpenEdition}

1 Journals

\section{Edizione digitale}

URL: http://journals.openedition.org/studifrancesi/6338

DOI: $10.4000 /$ studifrancesi.6338

ISSN: 2421-5856

\section{Editore}

Rosenberg \& Sellier

\section{Edizione cartacea}

Data di pubblicazione: 1 novembre 2010

Paginazione: 565

ISSN: 0039-2944

\section{Notizia bibliografica digitale}

Marco Stupazzoni, «"La Commedia umana" di Balzac. Omaggio al romanziere assoluto, a cura di Alessandro Demma», Studi Francesi [Online], 162 (LIV | III) | 2010, online dal 30 novembre 2015, consultato il 11 janvier 2021. URL: http://journals.openedition.org/studifrancesi/6338 ; DOI: https:// doi.org/10.4000/studifrancesi.6338

Questo documento è stato generato automaticamente il 11 janvier 2021.

\section{(c) $(1) \ominus$}

Studi Francesi è distribuita con Licenza Creative Commons Attribuzione - Non commerciale - Non opere derivate 4.0 Internazionale. 


\title{
"La Commedia umana" di Balzac. Omaggio al romanziere assoluto, a cura di Alessandro Demma
}

\author{
Marco Stupazzoni
}

\section{NOTIZIA}

AA. VV., "La Commedia umana" di Balzac. Omaggio al romanziere assoluto, a cura di Alessandro DEMMA, Milano, Skira, 2009, pp. 63, ill.

Il volume presenta il catalogo della mostra allestita presso il Castello di Rivalta (provincia di Torino) dal 26 settembre all'8 novembre 2009: questo importante evento ha inteso celebrare il romanziere francese nel ricordo del suo soggiorno nell'antico maniero piemontese il 10 agosto 1836 dove Balzac scrisse Le Cheval de Saint Martin in onore della contessa Polissena di Benevello. Per l'occasione, otto artisti italiani contemporanei hanno voluto fornire con le loro opere, e attraverso tecniche e linguaggi diversi, una particolare visione della società del nostro tempo confrontandola con quella descritta dallo scrittore due secoli prima. Su questo particolare aspetto, riflette Alessandro DEMMA, curatore del catalogo, nell'intervento che inaugura le pagine del volume (pp.13-15 e 16-18): egli osserva, infatti, che «attraverso l'utilizzo di differenti linguaggi (pittura, scultura, fotografia, video, installazione), confrontandosi con l'opera di Balzac e con gli spazi del Castello di Rivalta, gli artisti interpretano e riattualizzano [...] una nuova possibile visione di Balzac sulla commedia umana contemporanea» (p. 13). Sul romanzo Le Cousin Pons, sulla figura del collezionista e sulle riflessioni balzachiane intorno al sistema dell'arte, si sofferma Angelo TRIMARCo (pp. 19-20 e 21-22), mentre Stefania zULIANI (Chimere. Balzac e il capolavoro possibile, pp. 23-25 e 26-28) sottolinea la singolare originalità di Sarrasine, un racconto nel quale «si manifesta con dissimulata potenza la capacità di rivelazione insita in ogni autentico capolavoro, origine ed esito dell'opera stessa [...], dispositivo comunque sfuggente alle 
regole della ragione, alle prescrizioni di un'estetica che si sottrae agli umori, alle contraddizioni impure della produzione» (p. 23).

2 Tra le tematiche affrontate dai diversi artisti (il duo AfterAll, Maura Banfo, Filippo Centenari, Stanislao Di Giugno, Paolo Grassino, Mariangela Levita, Domenico Antonio Mancini, Perino \& Vele), figurano l'analisi dello sguardo balzachiano come esperienza di confine tra realtà e visione, il tema religioso legato a quello del gioco d'azzardo, la metafora della città, il mito dell'androgino, i territori della patologia sociale in relazione con i nuovi stili di vita e i nuovi modelli della civiltà metropolitana contemporanea. 